\title{
The $\gamma$-irradiation Effect on the Optical Properties of CdTe Thin Films Deposited by Thermal Evaporation Technique
}

\author{
Feras AFANEH ${ }^{1}$ *, Mohammed OKASHA ${ }^{1}$, Khalil J. HAMAM ${ }^{2}$, Adel SHAHEEN ${ }^{1}$, \\ Mufeed MAGHRABI ${ }^{1}$, Bashar LAHLOUH ${ }^{3}$, Hassan K. JUWHARI ${ }^{3}$
}

\author{
${ }^{1}$ The Hashemite University, Physics Department, Zarqa 13133, Jordan \\ ${ }^{2}$ Tafila Technical University, Applied Physics Department, Tafila 66110, Jordan \\ ${ }^{3}$ University of Jordan, Physics Department, Amman 11942, Jordan \\ crossref http://dx.doi.org/10.5755/j01.ms.24.1.17607
}

Received 16 February 2017; accepted 23 May 2017

\begin{abstract}
CdTe thin films of $50 \mathrm{~nm}$ thickness have been deposited on glass substrates by thermal vacuum evaporation technique and the $\gamma$-irradiation effect on their optical properties has been investigated. Transmittance and reflectance have been measured at normal incidence, in the visible region from 400 to $700 \mathrm{~nm}$, and were used to evaluate the optical parameters and the band gap energy for CdTe thin films before and after $\gamma$-irradiation. Structure and surface morphology before and after $\gamma$ irradiation were investigated using X-ray diffraction (XRD) analysis and scanning electron microscope (SEM) respectively. XRD pattern of the as-deposited CdTe film shows an amorphous nature. Crystalline structure was observed to improve when samples were exposed to $\gamma$-irradiation at doses from $40-120 \mathrm{kGy}$ in the (111) plane of the cubic zincblende structure. SEM shows a change in the surface morphology of CdTe films as a consequence of $\gamma$-irradiation compared to as-deposited sample. The optical properties such as refractive index, extinction coefficient, dielectric constant were found to decrease with the increase of the dose of $\gamma$-irradiation. Energy band gap was found to decrease from $2.47 \mathrm{eV}$ for the as-deposited down to $2.20 \mathrm{eV}$ for $120 \mathrm{kGy}$ (blue shift compared to bulk CdTe), that was attributed to the small thin film thickness.

Keywords: cadmium telluride, thin films, optical properties, $\gamma$-irradiation.
\end{abstract}

\section{INTRODUCTION}

Cadmium telluride (CdTe) has received the attention of scholars for several decades due to its attractive electrical and optical properties. Furthermore, CdTe has a low sublimation temperature that makes it a suitable candidate for physical vapor deposition techniques such as thermal evaporation method [1]. Therefore, it became one of the most promising candidates for optoelectronic applications such as photovoltaic cells accompanied with low cost and good efficiency [2-4], nonlinear integrated optical devices [5], light emitting diodes [6], photometers and radiometers devices such as IR detectors, X-ray detectors, gamma-ray detectors [7-9] and electronic applications such as field effect transistors [10].

Optical properties and the structure of CdTe thin films were found to have a direct dependence on the film's thickness as reported by Lalitha et al. [11], and Patil et al. [12]. Kim et al. [13] studied the effect of annealing temperature on the optical properties of the CdTe thin films. Rahman et al. [14] showed that better films structure and optical properties can be achieved by increasing the annealing time. On the other hand, exposing CdTe to gamma radiation leads to a change in its structural and electrical properties as reported by Maity et al. [15].

Previous studies on CdTe thin films were focused on the variation of structure and optical properties with deposition conditions such as deposition time rate [16], substrates temperature [17], the film's thickness [18, 19]. and the source temperature [20]. In this work, we studied the optical properties and the optical parameters of very thin films of CdTe $(50 \mathrm{~nm})$ when exposed to different doses of $\gamma$ irradiation. Very thin films are important in solar cell fabrication based on CdTe semiconductor. Understanding the effect of $\gamma$-irradiation on the structure and optical properties such as band gap, refractive index, absorption coefficient, and dielectric constant (real and imaginary parts) of CdTe thin film without pre-annealing is important for fabrication of cheap and efficient optoelectronic and electronic applications.

\section{EXPERIMENTAL DETAILS}

Glass substrates $(2 \times 2 \mathrm{~cm})$ were cleaned by acetone, methanol, and distilled water respectively. CdTe powder (99.999\% pure, purchased from Balzers), was evaporated using thermal evaporation technique at room temperature and under a pressure of $8 \times 10^{-8}$ torr. The evaporation rate was set at $5 \mathrm{~A} / \mathrm{s}$ and a film's thickness of $500 \pm 2 \AA$ was achieved and measured using the quartz crystal monitor (QCM). The films were irradiated with $1.25 \mathrm{MeV} \gamma$-rays using the $\mathrm{Co}^{60}$ source at Jordan Atomic Energy Commission. The irradiation dose was varied from 40 to $120 \mathrm{kGy}$.

The transmission and reflection were measured in the visible wavelength range of $400-700 \mathrm{~nm}$ at nearly normal incidence using FilmTek 3000 system (SCI) and Cary 50 ultraviolet-visible (UV-vis) double beam spectrophotometer

\footnotetext{
${ }^{*}$ Corresponding author. Tel.: +962-79-5380610.
}

E-mail address:afaneh@hu.edu.jo (F. Afaneh) 
(Agilent). The average error in measuring the reflection and transmission was estimated to be $\pm 4 \%$.

The optical parameters such as absorption coefficient $(\alpha)$, extinction coefficient $(k)$, and the refractive index $(n)$ were calculated using the following equations [21-24]:

$\alpha=\frac{1}{t} \ln \left[\frac{(1-R)^{2}}{2 T}+\left[\left(\frac{(1-R)^{2}}{2 T}\right)^{2}+R^{2}\right]^{\frac{1}{2}}\right]$

$k=\frac{\lambda \alpha}{4 \pi}$

$n=\left(\frac{1+R}{1-R}\right)+\left[\left(\frac{4 R}{(1-R)^{2}}\right)-k^{2}\right]^{\frac{1}{2}}$,

where $(t)$ is the sample thickness, $(T)$ and $(R)$ are the transmission and the reflection coefficient respectively. Furthermore, the real and the imaginary parts of the dielectric constant ( $\varepsilon^{\prime}$ and $\varepsilon^{\prime \prime}$ respectively), were calculated using the following equations $[25,26]$ :

$\varepsilon^{\prime}=n^{2}-k^{2}$

$\varepsilon^{\prime \prime}=2 n k$.

\section{RESULTS AND DISCUSSION}

The typical X-ray pattern for CdTe's cubic structure (zinc-blende) was reported to be observed at $2 \theta=23.7^{\circ}$, $39.3^{\circ}$, and $46.6^{\circ}$, which corresponds to diffraction peaks from (111) and (220) and (311) planes respectively according to JCPDS file no. 15-0770.

The XRD patern for our samples before (as-deposited) and irradiated by different doses are shown in Fig. 1. An amorphous nature was observed for the as-deposited (nonirradiated) as shown in Fig. $1 \mathrm{a}$, the broad peak between $20^{\circ}-30^{\circ}$ which is usually observed in glass's $\mathrm{x}$-ray diffraction pattern [27], that could be related to substrate's scattering because of the small CdTe thickness $(50 \mathrm{~nm})$ [28]. The X-ray pattern for the irradiated samples, shows an increase in the crystalline nature due to irradiation; the preferred orientation peak at $2 \theta=23.7^{\circ}$ confirms the creation of cubic zinc blend structure [29]. It can be observed that the peak's intensity is increasing and becomes sharper as the irradiation dose increases. The increase in the peak's intensity has been approved to be related to the enhancement of crystals growth and the grain size in the irradiated films [29, 30]; other peaks for CdTe such as (220) and (311) planes are weak, the one intense peak is suggesting a disordered nature of the system. Another peak was observed at $2 \theta=28.88^{\circ}$ which could be related to the substrates -Si glass (111)- according to JCPDS file no. 271402 or corresponds to the (102) plane, which usually observed in the annealed CdTe films as reported by [31]. The effect of $\gamma$-irradiation on the CdTe thin film's surface shows random deformations as shown in Fig. 2 (b-80 kGy, $\mathrm{c}-100 \mathrm{kGy}$ and $\mathrm{d}-120 \mathrm{kGy}$ ) respectively. The irradiated samples became darker as the dose of irradiation increases compared to the as-deposited thin film as shown in Fig. 2 a. There was no systematic correlation between the absorbed dose and the distribution of the deformation spots observed on the thin film surface. Scanning Electron Microscopy (SEM) was then used to further assessment of the CdTe thin film's surface morphology before and after irradiation. Fig. 2 a shows a smooth surface morphology with pinholes were observed for as-deposited (without irradiation). Pinholes are usually observed for imperfect coalescence of the CdTe grains during deposition especially for small thin films thicknesses as in our present work. Fig. $2 \mathrm{~b}$ shows a rough and spotting surface of irradiated CdTe thin film at $80 \mathrm{kGy}$, which could be attributed to the interaction of energetic $\gamma$-ray photons with atoms in its path. Therefore, excitation and ionization resulted in the material's atoms that cause a change in the materials structure [32, 33].

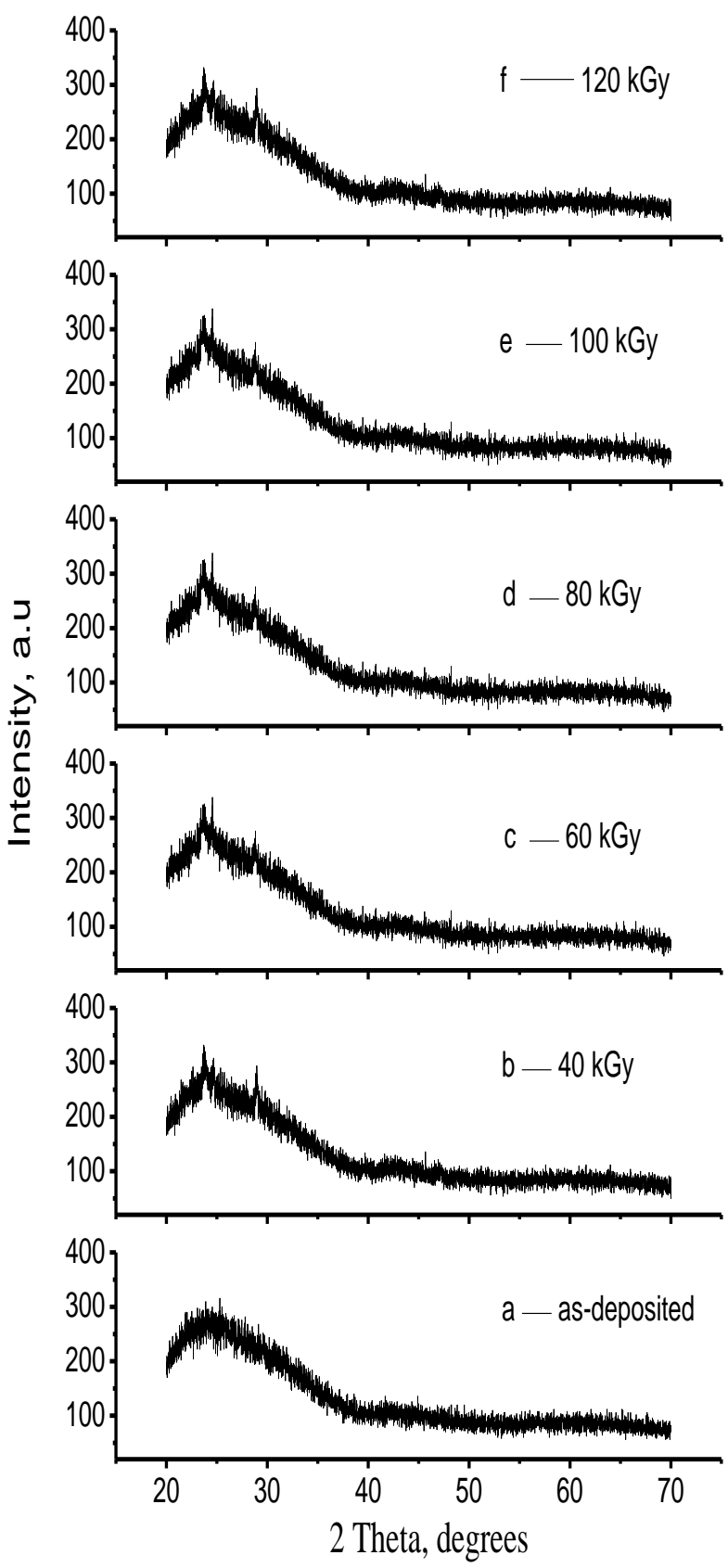

Fig. 1. The XRD patterns for CdTe thin films: a-as-deposited, and $\gamma$-irradiated with doses b-40kGy; c-60 kGy; $\mathrm{d}-80 \mathrm{kGy}, \mathrm{e}-100 \mathrm{kGy} ; \mathrm{f}-120 \mathrm{kGy}$

Fig. $4 \mathrm{a}$ shows that the transmittance of irradiated samples is increasing compared to the as-deposited sample, while the reflectance of the irradiated samples is decreasing as shown in Fig. 4 b. 


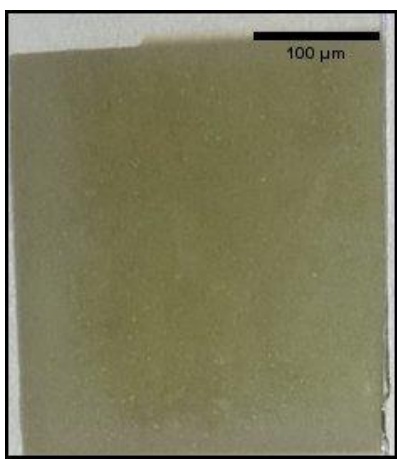

a

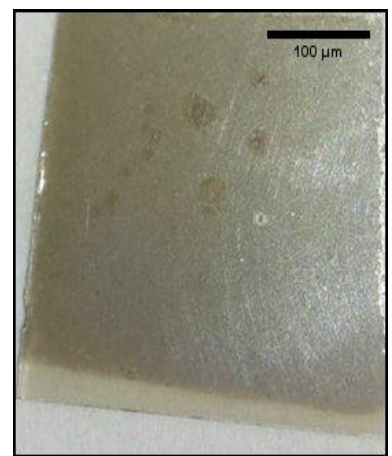

b

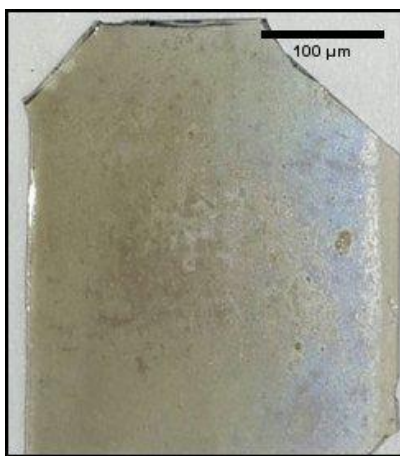

$\mathrm{c}$

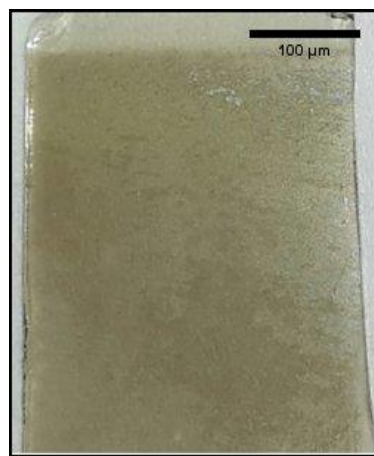

d

Fig. 2. Camera images show the effect of $\gamma$-irradiation on the CdTe thin film's surface: a-before irradiation (as-deposited) and after irrdiation at b-80 kGy; c-100 kGy; d-120 kGy

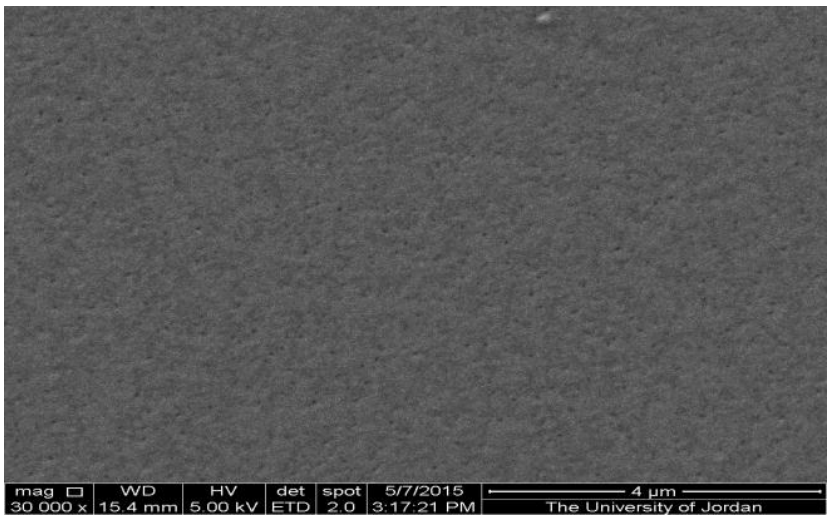

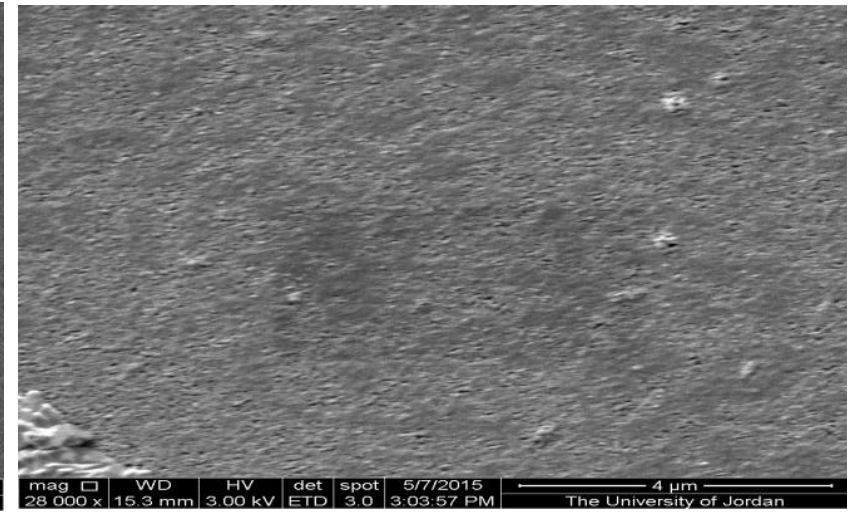

b

Fig. 3. Scanning electron microscopy (SEM) images show the surface morphology of CdTe films: a-before (as deposited) and $\mathrm{b}$-after $\gamma$-irradiation at $80 \mathrm{kGy}$
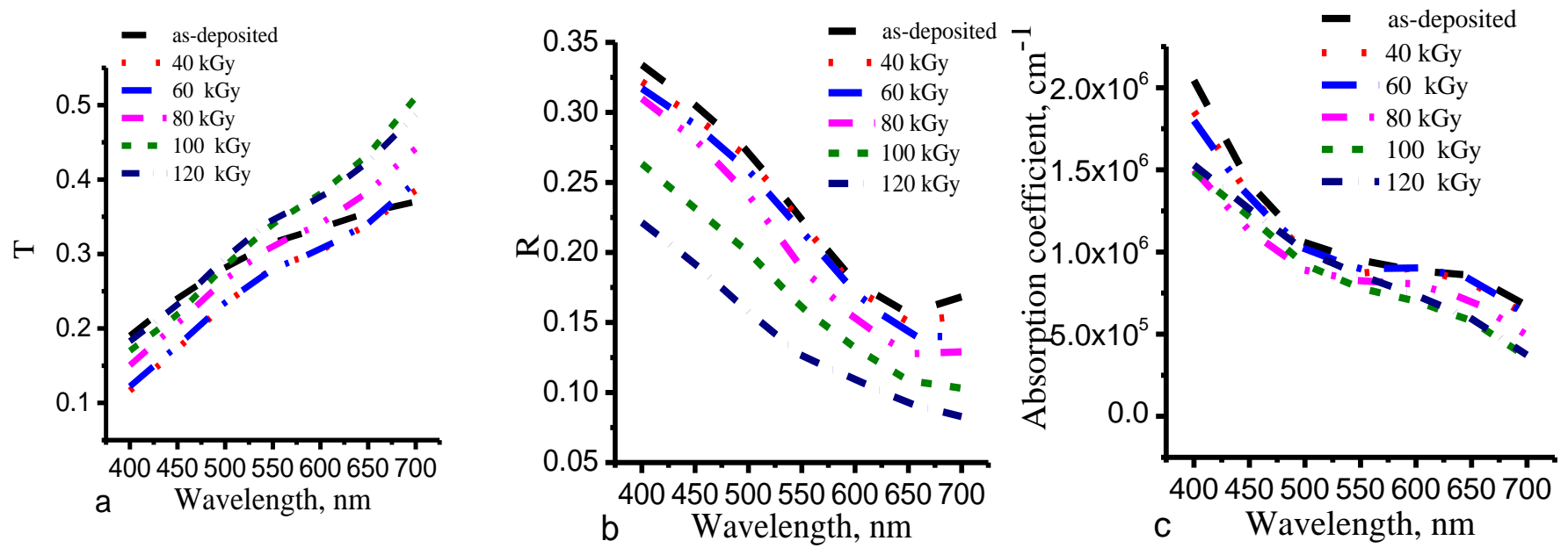

Fig. 4. a-transmission; b-reflection; c-absorption coefficient of CdTe thin films as a function of wavelength

No substantial changes in transmittance and reflectance were observed for the samples irradiated at $40 \mathrm{kGy}$ and $60 \mathrm{kGy}$, while the effect of irradiation was clearly observed for the samples irradiated at $80-120 \mathrm{kGy}$. At low wavelength (high photon energy), the absorbance of the irradiated samples has slightly lower values compared to the as-deposited samples, while at high wavelengths (low photon energy) the values are lower. The absorption coefficient is also decreasing as the wavelengths increases as shown in Fig. 4 c.

The refractive index $n$ values are decreasing as the wavelength increases as shown in Fig. 5 a. It can be observed that refractive index is decreasing as the irradiation dose increasing, which supports that the material became more transparent as the irradiation dose increases, consistent with what have been observed in the 
transmittance behavior. The extinction coefficient $k$ was also found to decrease with increasing wavelength and its values were lower than the as- deposited sample as shown in Fig. 5 b. Both parameters $n$ and $k$ don't have a welldefined maximum or minimum as a function of the wavelength, except a little kink at between 600-650 nm, which represents the absorption edge [24]. Refractive index varies in the range from $\sim 2$ to $\sim 4$, while the extinction coefficient varies from $\sim 0.1$ to $\sim 0.65$ as a function of wavelength for different doses of irradiation. Table 1 shows the variation of $n$ and $k$ at $\lambda=550 \mathrm{~nm}$.

Table 1. The real part of the dielectric constants $\left(\varepsilon^{\prime}\right)$, the absorption coefficient $(\alpha)$, refractive index $(n)$, and the extinction coefficient $(k)$ at $\lambda=550 \mathrm{~nm}$

\begin{tabular}{|c|c|c|c|c|}
\hline Dose, $\mathrm{kGy}$ & $\varepsilon^{\prime}$ & $\alpha \times 10^{5}, \mathrm{~cm}^{-1}$ & $n$ & $k$ \\
\hline 0 & 7.24 & 9.50 & 2.721 & 0.410 \\
\hline 40 & 7.24 & 8.71 & 2.716 & 0.376 \\
\hline 60 & 6.96 & 8.97 & 2.666 & 0.387 \\
\hline 80 & 6.01 & 8.23 & 2.477 & 0.355 \\
\hline 100 & 5.07 & 7.79 & 2.276 & 0.337 \\
\hline 120 & 3.91 & 8.50 & 2.012 & 0.370 \\
\hline
\end{tabular}
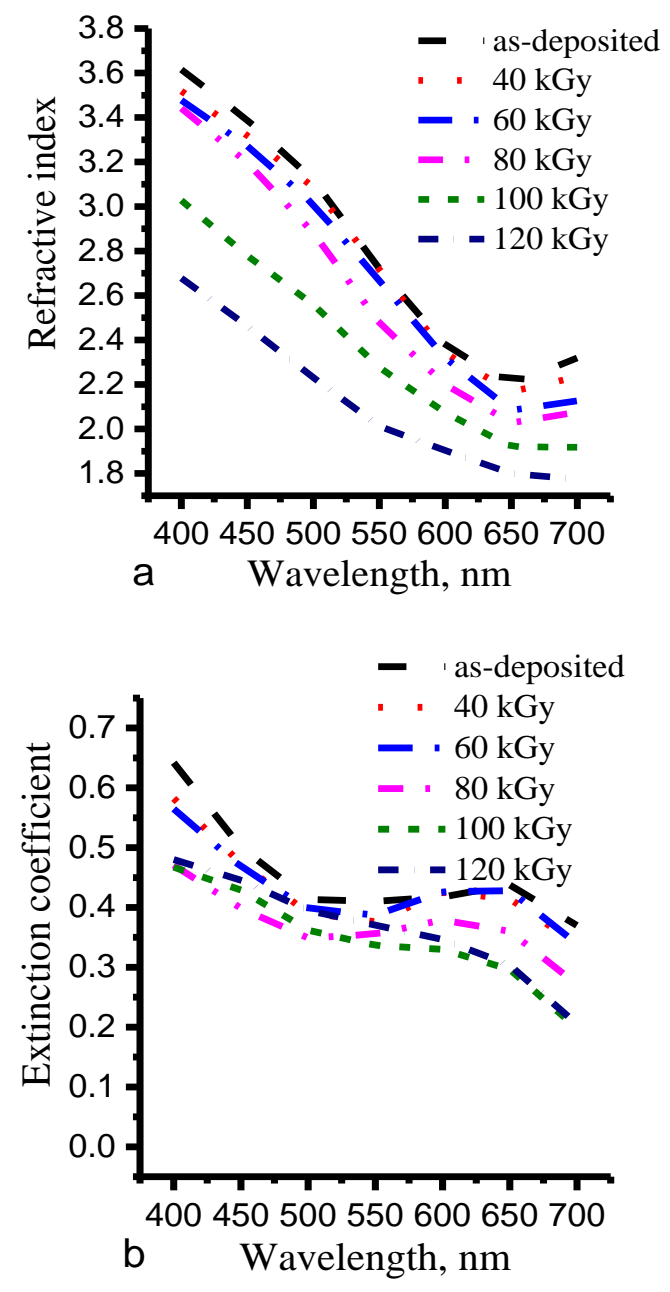

Fig. 5. $a$-refractive index; b-extinction coefficient versus wavelength for as-deposited and $\gamma$-irradiated CdTe thin films

The behavior and values of $n$ and $k$-at a similar range of the wavelengths- for the as-deposited sample were consistent with what reported by scholars such as Lalitha et al. [34], El-Shazly and El-Shair [35] and Punitha et al [36]. The variation in $k$ and $n$ values with irradiation reveals that there is a structural change in the films.

Refractive index and extinction coefficient values were used to calculate the real $\left(\varepsilon^{\prime}\right)$ and the imaginary parts $\left(\varepsilon^{\prime \prime}\right)$ of the dielectric constant. The real part $\left(\varepsilon^{\prime}\right)$ was found to decrease with increasing wavelength and the dose of $\gamma$ irradiation as shown in Fig. 6 a. The behavior and values of $\varepsilon^{\prime}$ were almost consistent with the calculated values of $\varepsilon^{\prime}$ by Kim et al. [13], using the spectroscopic ellipsometry. Table 1 shows the effect of irradiation dose on the real dielectric constant $\varepsilon^{\prime}$ at $\lambda=550 \mathrm{~nm}$. On the other hand, the imaginary part of the dielectric constant $\varepsilon$ " was decreasing with increasing the wavelength and the dose of $\gamma$-irradiation as shown in Fig. 6 b.
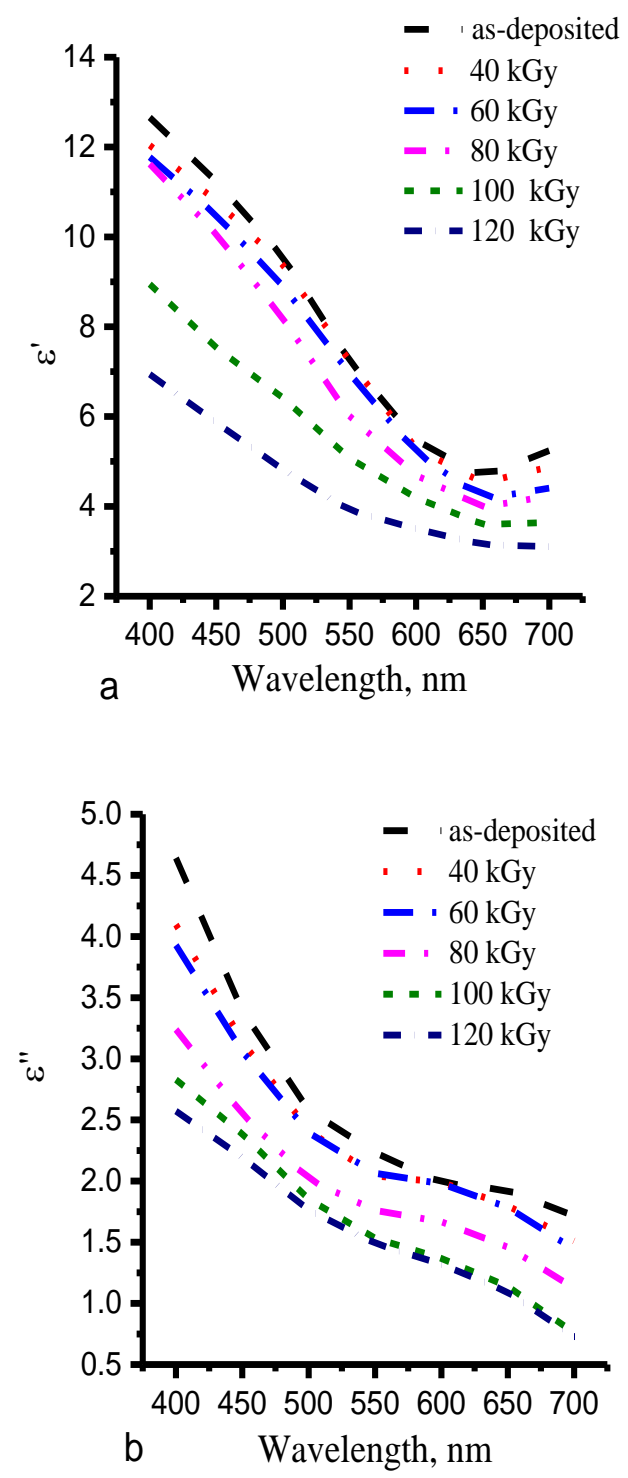

Fig. 6. $\mathrm{a}$-dielectric constants $\left(\varepsilon^{\prime}\right)$; $\mathrm{b}$-the imaginary part of the dielectric constant $\left(\varepsilon^{\prime \prime}\right)$ as a function of the wavelength for CdTe thin films

The absorption coefficient is related to the incident photon energy(hv) by [29]:

$\alpha h v=A\left(h v-E_{g}\right)^{m}$, 
where $A$ is a parameter that depends on the transition probability, $h$ is the Planck's constant, $v$ is the frequency of the light, $m$ is a fitting parameter that takes values $0.5,1$, 1.5, 2 and 3, depending on the type of electron transition and $E_{\mathrm{g}}$ is the energy band gap. We found the best fitting is when $m=0.5$ which is consistent with the literature [37-39]. Eq. 6 was used to find the optical gap $\left(E_{\mathrm{g}}\right)$ by extrapolation the straight line toward the abscissa $\left((\alpha h v)^{2}=0\right)$, as shown in Fig. 7. The higher value of $E_{\mathrm{g}}$ was recorded for the asdeposited thin film, which recorded a value of $2.47 \mathrm{eV}$ compared to the bulk CdTe band gap which is known as $\sim 1.5 \mathrm{eV}$ (a blue shift) $[24,38]$. The calculated values of band gap energies were very close to the that values reported for the nano-structure size of CdTe whih could be because of the small film thickness. A small grain size and an existence of strain in the structure are expected due to the small thickness of the thin film $[40,41]$. The recorded band gap energy values for our studied CdTe thin films make it an appropriate candidate for the fabrication of electroluminescent display devices [41, 42]. Table 2 shows the values of the $E_{g}$, where they depend on the irradiation dose; the energy gap decreased from $(2.47 \mathrm{eV})$ for nonirradiated CdTe thin film to $(2.20 \mathrm{eV})$ for the $120 \mathrm{kGy}$ dose of irradiation. The decrease in the band gap energy could be attributed to the increasing of crystallinity as confirmed by the XRD measurements. The irradiation could introduce new energy levels in the forbidden gap which causes radical changes in the carrier concentration in the material [43].

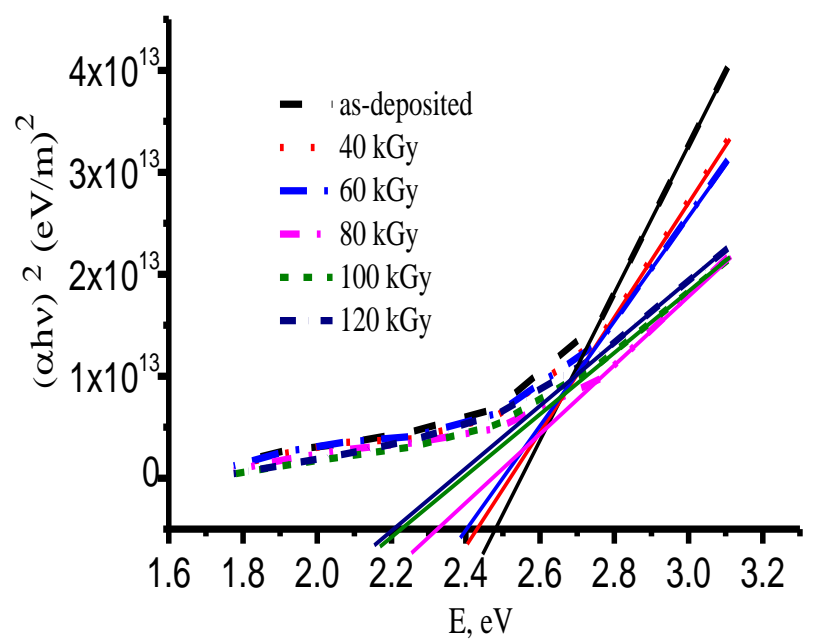

Fig. 7. The band gap energy of as-deposited and $\gamma$-irradiated CdTe thin films

Table 2. Band gap energy of CdTe at different irradiations

\begin{tabular}{|c|c|}
\hline Dose, $\mathrm{kGy}$ & Band gap energy, eV \\
\hline 0 & 2.47 \\
\hline 40 & 2.43 \\
\hline 60 & 2.40 \\
\hline 80 & 2.31 \\
\hline 100 & 2.22 \\
\hline 120 & 2.20 \\
\hline
\end{tabular}

\section{CONCLUSIONS}

The effect of $\gamma$-irradiation on the CdTe thin films $(50 \mathrm{~nm})$ deposited by thermal vacuum evaporation technique on glass substrates were studied. It was found that exposing CdTe thin films to $\gamma$-irradiation helps to improve its structure from an amorphous phase into a crystalline structure in the (111) plane of the cubic zinc-blende structure. The SEM images show a change in the surface morphology as a consequence of $\gamma$-irradiation compared to as-deposited sample. Optical parameters were studied in the spectral range from 400 to $700 \mathrm{~nm}$. It was found that transmittance was increasing and reflectance was decreasing with increasing the dose of $\gamma$-irradiation. Furthermore, refractive indices, extinction coefficients, absorption coefficient and dielectric constant were decreased, as the dose of irradiation increase, due to the change in the material's structure. Energy band gap $\left(E_{\mathrm{g}}\right)$ was found to decrease from $2.47 \mathrm{eV}$ for the as-deposited down to $2.20 \mathrm{eV}$ for $120 \mathrm{kGy}$ (blue shifted compared to bulk $\mathrm{CdTe}$ ), that could be attributed to the formation of small grain size because of the small thin film's thickness. The small thickness of CdTe and the resulted energy gaps before and after $\gamma$-irradiation could be used to fabricate optoelectronic applications with higher energy band gap suh as electroluminescent display devices.

\section{REFERENCES}

1. Ismail, B.B., Gold, R.D. Structural and Electronic Properties of Evaporated Thin Films of Cadmium Telluride Physica Status Solidi A 115 (1) 1989: pp. 237-245. http://dx.doi.org/10.1002/pssa.2211150126

2. Naseem, S., Nazir, D., Mumtaz, R., Hussain, K. Evaporated thin films of CdS and CdTe: optimization for photovoltaic applications Journal of Materials Science \& Technology 12 1996: pp. 89-94.

3. Ray, S.C., Mallick, K. Cadmium Telluride (CdTe) Thin Film for Photovoltaic Applications International Journal of Chemical Engineering and Applications 4 (4) 2013: pp. $183-186$. http://dx.doi.org/10.7763/IJCEA.2013.V4.290

4. Toma, O., Ion, L., Girtan, M., Antohe, S. Optical, Morphological and Electrical Studies of Thermally Vacuum Evaporated Cdte Thin Films for Photovoltaic Applications Solar Energy 108 2014: pp. 51-60. https://doi.org/10.1016/j.solener.2014.06.031

5. Angell, M.J., Emerson, R.M., Hoyt, J.L., Gibbons, J.F. Growth of Alternating (1OO)/(L11)-Oriented II-VI Regions for Quasi-Phase- Matched Nonlinear Optical Devices on Gaas Substrates Applied Physic Letters $64(23)$ 1994: pp. $3107-3109$.

http://dx.doi.org/10.1063/1.111362

6. Zhao, J., Bardecker, J.A., Munro, A.M., Liu, M.S., Niu, Y., Ding, I.K., Luo, J., Chen, B., Jen, A.K.Y., Ginger, D.S. Efficient $\mathrm{CdSe} / \mathrm{CdS}$ Quantum Dot LightEmitting Diodes Using a Thermally Polymerized Hole Transport Layer Nano Letters 6 (3) 2006: pp. 463-467. http://dx.doi.org/10.1021/n1052417e

7. Szeles, C. CdZnTe and CdTe Materials for X-ray and Gamma Ray Radiation Detector Applications Physica Status Solidi B 241 (3) 2004: pp. 783-790. http://dx.doi.org/10.1002/pssb.200304296

8. Harris, R.J., Johnston, G.T., Kepple, G.A., Krok, P.C., Mukai, H. Infrared Thermooptic Coefficient Measurement Of Polycrystalline ZnSe, ZnS, CdTe, $\mathrm{CaF}(2)$, and $\mathrm{BaF}(2)$, Single Crystal KCl, and TI-20 Glass Applied Optics 16 (2) 1977: pp. $436-438$. http://dx.doi.org/10.1364/AO.16.000436 
9. Al-Douri, A.J., Al-Shakily, F.Y., Alnajjar, A.A., Alias, M.F.A. The Role of Dopant Concentration on Conductivity and Mobility of CdTe Thin Films Advances in Condensed Matter Physics 2011 2011: pp. 1-6.

http://dx.doi.org/10.1155/2011/910967

10. Dreifus, D.L., Kolbas, R.M., Tassitino, J.R., Harper, R.L., Bicknell, R.N., Schetzina, J.F. Electrical Properties of Cdte Metal-Semiconductor Field Effect Transistors Journal of Vacuum Science \& Technology A: Vacuum, Surfaces, and Films 6 1988: pp. 2722-2724.

http://dx.doi.org/10.1116/1.575493

11. Lalitha, S., Sathyamoorthy, R., Senthilarasu, S., Subbarayan, A., Natarajan, K. Characterization of CdTe Thin Films-Dependence of Structural and Optical Properties on Temperature and Thickness Solar Energy Materials and Solar Cells 82 2004: pp. 187-199.

https://doi.org/10.1016/j.solmat.2004.01.017

12. Patil, S.S., Pawar, P.H. Structural and Optical Studies of Thermally Evaporated CdSexTe1-x Thin Films Journal of Chemical, Biological and Physical Sciences 2 (3) 2012: pp. $1472-1484$.

13. Kim, C.C., Daraselia, M., Garland, J.W., Sivananthan, S. Temperature Dependence of the Optical Properties of CdTe Physical Review B 56 (8) 1997: pp. 4786-4797. http://dx.doi.org/10.1103/PhysRevB.56.4786

14. Rahman, K.S., Khan, N.A., Imamzai, M.N., Akhtaruzzaman, M., Sopian, K., Alothman, Z.A., Amin, N. Investigation of tThe Annealing Time Effects on $\mathrm{Cu}$ Deposited Cdte Thin Films For Photovoltaic Application IEEE Regional Symposium on Micro and Nanoelectronics (RSM) 2015:pp. 1-4. http://dx.doi.org/10.1109/RSM.2015.7355006

15. Maity, K.T., Sharma, L.S. Effect of Gamma Radiation on Optical and Electrical Properties of Tellurium Dioxide Thin Films Bulletin of Materials Science 31 2008: pp. $841-846$.

http://dx.doi.org/10.1007/s12034-008-0134-x

16. Ghorannevis, Z., Akbarnejad, E., Ghoranneviss, $M$. Effects of Various Deposition Times and RF Powers on CdTe Thin Film Growth Using Magnetron Sputtering Journal of Theoretical and Applied Physics 10 (3) 2016: pp. 225 -231. http://dx.doi.org/10.1007/s40094-016-0219-7

17. Uda, H., Ikegami, S., Sonomura, H. Effect of Substrate Temperature on the Photovoltaic Properties of a CdS/CdTe Solar Cell Japanese Journal of Applied Physics 29(10) 1990: pp. 2003-2007. http://dx.doi.org/10.1143/JJAP.29.2003

18. Skafarman, W.N., Birkmire, R.W., $\quad$ Fardig, D.A., Mc Candless, B.E., $\quad$ Mondal, A., $\quad$ Phillips, J.E., Varrin, R.D. Advances in CuInSe2 and CdTe Thin Film Solar Cells 30 1991: pp. 61-67.

http://dx.doi.org/10.1016/0379-6787(91)90038-Q

19. JiménezSandoval, S., MeléndezLira, M., HernándezCalderón, I. Crystal Structure and Energy Gap of CdTe Thin Films Grown by Radio Frequency Sputtering Journal of Appied Physics 72 (9) 1992: pp. 4197-4202. http://dx.doi.org/10.1063/1.352230

20. Rusu, G.G. On the Electrical and Optical Properties of Nanocrystalline CdTe Thin Films Journal of Optoelectronic and Advanced Materials 3 (4) 2001: pp. $861-866$.

21. Callister, D.W., Rethwisch, G.D. Materials Science and Engineering: An introduction. 8th edition, John Wiley \& sons Inc, Asia, 2011.
22. Begam, M.R., Rao, N.M., Kaleemulla, S., Shobana, M., Krishna, N.S., Kuppan, M. Effect of Substrate Temperature on Structural and Optical Properties of Nanocrystalline CdTe Thin Films Deposited by Electron Beam Evaporation Journal of nano- and Electronic Physics 5 (3) 2013: pp. 3019-3019.

23. Di Giulio, M., Micocci, G., Rella, R., Siciliano, P., Tepore, A. Optical Absorption of Tellurium Suboxide Thin Films Physica Status Solidi A $136(2)$ 1993: pp. K101-104. http://dx.doi.org/10.1002/pssa.2211360236

24. Khairnar, P.U., Bhavsar, S.D., $\quad$ Vaidya, U.R., Bhavsar, P.G. Optical Properties of Thermally Evaporated Cadmium Telluride Thin Films Materials Chemistry and Physics 80 2003: pp. 421-427. https://doi.org/10.1016/S0254-0584(02)00336-X

25. Khrypunov, G., Romeo, A., Kurdesau, F., Batzer, L.D., Zogg, H., Tiwari, N.A.. Recent Development in Evaporated CdTe Solar Cells Solar Energy Materials and Solar Cells 90 2006: pp. 664-677. https://doi.org/10.1016/j.solmat.2005.04.003

26. Tiffo, E., Elimbi, A., Manga, J.D., Tchamba, A.B.. Red Ceramics Produced From Mixtures of Kaolinite Clay and Waste Glass Brazilian Journal of Science and Technoogy 2 (4) 2015: pp. $1-13$. http://dx.doi.org/10.1186/s40552-015-0009-9

27. Nassar, Z.M., Yukselici, M.H., Bozkurt, A.A. Structural and Optical Properties of CdTe Thin Film: A Detailed Investigation Using Optical Absorption, XRD, and Raman Spectroscopies Physica Status Solidi B 253 (6) 2016: pp. $1104-1114$. http://dx.doi.org/10.1002/pssb.201552433

28. Gordillo, G., $\quad$ Flrez, J.M., $\quad$ Hernández, L.C. Preparation and Characterization of CdTe thin Films Deposited by CSS Solar Energy Materials and Solar Cells 37 1995: pp. 273-281. https://doi.org/10.1016/0927-0248(95)00020-8

29. Bacaksiz, E., Basol, B., Altunbas, M., Novruzov, V., Yanmaz, E., Nezir, S. Effects of Substrate Temperature and Post-Deposition Anneal on Properties of Evaporated Cadmium Telluride Films Thin Solid Films 515(5) 2007: pp. 3079-3084. https://doi.org/10.1016/j.tsf.2006.08.026

30. Shree, B.L., Priya, S.S., Ranjani, P.T., Karthick, P., Jeyadheepan, K., Sridharan, M. Influence of CdTe Thickness on the Properties of Vacuum Evaporated CdSe/CdTe Bilayer Materials Today: Proceedings 3 2016: pp. 1494-1501. https://doi.org/10.1016/j.matpr.2016.04.033

31. Rahman, K.S., Haque, F., Khan, N.A., Islam, M.A., Alam, M.M., AlOthman, Z.A., Sopian, K., Amin, N. Influence of Thermal Annealing on CdTe thin Film Deposited by Thermal Evaporation Technique. 3rd International Conference on the Developments in Renewable Energy Technology (ICDRET), 2014. https://doi.org/10.1109/ICDRET.2014.6861722

32. O'Donnell, J.H., Sangster, D.I. Principles of Radiation Chemistry. Edward Arnold, London, 1970.

33. Ausloos, P. Fundamental Processes in Radiation Chemistry. John Wiley \& Sons, New York, 1968.

34. Lalitha, S., Karazhanov, S.Z., Ravindran, P., Senthilarasu, S., Sathyamoorthy, R., Janabergenov, J. Electronic Structure, Structural and Optical Properties of Thermally Evaporated CdTe Thin Films Physica B 387 2007: pp. $227-238$. 
https://doi.org/10.1016/j.physb.2006.04.008

35. El-Shazly, A., El-Shair, H. Some Parameters Affecting The Optical Constants of CdTe Thin Evaporated Films Thin Solid Films 78 (3) 1989: pp. 287-293. https://doi.org/10.1016/0040-6090(89)90595-6

36. Punitha, K., $\quad$ Sivakumar, R., $\quad$ Sanjeeviraja, C., Ganesan, V. Influence of Post-Deposition Heat Treatment on Optical Propertiesderived From UV-vis of Cadmium Telluride (CdTe) Thin Films Depositedon Amorphous Substrate Applied Surface Science 344 2015: pp. 89-100. https://doi.org/10.1016/j.apsusc.2015.03.095

37. Ikmayies, J.S., Bitar, A.N.R. Characterization of Vacuum Evaporated CdTe Thin Films Prepared at Ambient Temperature Material science semiconductor processing 16 2013: pp. $118-125$. https://doi.org/10.1016/j.mssp.2012.06.003

38. Issa, I.S. Radiation Effect on The Optical \& Structural Properties of CdTe: Zn Thin Films Ibn Al-Haitham Journal for Pure and Applied Science 26 2013: pp. 150-158.

39. Khan, R.Z, Zulfequar, M., Khan, S.M. Structural, Optical, Photoluminescence, Dielectric and Electrical Studies of Vacuum-Evaporated CdTe Thin Films Indian Journal of Material Science 35 2012: pp. 169-174. https://doi.org/10.1007/s12034-012-0274-x

40. Saha, S., Pal, U., $\quad$ Chaudiiuri, A.K., $\quad$ Rao, V.V., Banerjee, H.D. Optical Properties of CdTe Thin Films Physica Status Solidi A 114 1989: pp. 721-729. https://doi.org/10.1002/pssa.2211140236

41. Chen, W., Grouquist, D., Roark, J. Voltage Tunable Electroluminescence of CdTe Nanoparticle LightEmitting Diodes Journal of Nanoscience Nanotechnology 2 2002: pp. 47-53. http://dx.doi.org/10.1166/jnn.2002.067

42. Singh, V.P., Aguilera, A., Garcia, A., Morton, D.C. Modeling of Electron Transport and Luminance in $\mathrm{SrS}: \mathrm{Cu}$, Ag ACTFEL Display Devices IEEE Transactions on Electron Devices 48 (10) 2001: pp. 2242-2248. http://dx.doi.org/10.1109/16.954461

43. Rose, D.H., Hasoon, F.S., Dhere, R.G., Albin, D.S., Ribelin, R.M., Li, X.S., Mahathongdy, Y., Gessert, T.A., Sheldon, P. Fabrication Procedures and Process Sensitivities for CdS/CdTe Solar Cells Progress in Photovoltaics: Research and Appications 7 1999: pp. 331-340. http://dx.doi.org/10.1002/(SICI)1099159X(199909/10)7:5\%3C331::AID-PIP257\%3E3.0.CO;2-P 